Thorax, 1980, 35, 901-904

\title{
Management of massive haemoptysis with the rigid bronchoscope and cold saline lavage
}

\author{
ALAN A CONLAN AND SOLOMON S HURWITZ \\ From the Department of Cardio-Thoracic Surgery and Department of Medicine, \\ Baragwanath Hospital and University of the Witwatersrand, Johannesburg, South Africa
}

ABSTRACT Twelve successive patients with massive haemoptysis were treated by emergency rigid bronchoscopy and lavage of the bleeding lung with cold saline. All patients stopped bleeding during the procedure and all blood and clot was evacuated from the accessible airways. The bleeding source was localised to a lobe in seven cases, and lateralised in the remaining five patients. Two patients had a second haemorrhage during that hospital stay and cold saline lavage again terminated it. Further therapy, either surgical or medical was based on information obtained during the respite from haemorrhage achieved with this technique. There was no hospital mortality in the series.

The conservative management of haemoptysis is generally successful, but $10-15 \%$ of all patients with haemoptysis may bleed to a life-threatening extent. ${ }^{2}$ This figure includes patients with limited pulmonary reserve in whom the spillage of moderate amounts of blood into the tracheobronchial tree causes critical deterioration in lung function, and those in danger of asphyxiation from the sheer volume of blood aspirated. The various methods of management of lifethreatening haemoptysis include drug therapy endoscopic control measures (endobronchial balloon tamponade, topical adrenalin application, and lung isolation with double lumen endotracheal tubes), bronchial artery embolisation techniques, and lung resection. The performance of a pulmonary resection on a patient who is actively bleeding and whose respiratory reserve is unknown is necessarily hazardous. The occurrence of massive haemoptysis in poor risk patients has encouraged the development of nonsurgical methods of management. Our experience with emergency rigid bronchoscopy and cold saline lavage in 12 patients with massive haemoptysis forms the basis of this report. No similar experience has been reported.

Address for reprint requests: Dr Alan A Conlan, Principal CardioThoracic Surgeon, Department of Cardio-Thoracic Surgery, Medical School, University of the Witwatersrand, Hospital Street,
Johannesburg 2001, South Africa.

\section{Patients and methods}

During the period August 1978-June 1979 inclusive, 12 patients with massive haemoptysis were treated by the combined Thoracic Surgery and Respiratory Medicine Services of Baragwanath Hospital, Johannesburg. Our definition of massive haemoptysis was the expectoration of more than $600 \mathrm{ml}$ of blood within a 24-hour period after hospital admission. There were 11 men and one woman and all were black or of mixed race and from the poorest socioeconomic background. Eleven of the 12 patients were new cases to our services. The age range was from 28 to 60 years. After a preliminary assessment of the clinical and respiratory state our standard medical regimen for the management of continued haemoptysis was begun. The essentials of this regime were strict bedrest in the semi-sitting position, or posture with the radiologically normal lung uppermost. A controlled humidified oxygen and air mixture was given by face mask and diazapam $5 \mathrm{mg}$ every six hours was commenced. A large bore intravenous cannula was inserted into a peripheral vein and four units of whole blood were grouped and crossmatched. Arterial blood gases were obtained on admission and thereafter if clinical deterioration was suspected. The prothrombin index, platelet count, and blood creatinine, urea and electrolytes were estimated urgently. Good quality chest radiographs (posteroanterior and left lateral views) 
Table 1 Diagnosis and location of pathology

\begin{tabular}{|c|c|c|c|c|c|}
\hline Case & $\begin{array}{l}\text { Age } \\
(y r)\end{array}$ & Sex & Diagnosis & $\begin{array}{l}\text { Volume haemoptysis } \\
(\mathrm{ml} / 24 \mathrm{hr})\end{array}$ & Site of bleeding \\
\hline 1 & 51 & $\mathbf{M}$ & Bronchiectasis & 1000 & Left upper lobe \\
\hline 2 & 55 & $\mathbf{M}$ & Bronchiectasis & 1000 & Right lung \\
\hline 3 & 33 & $\mathbf{F}$ & Bronchiectasis & 600 & Right lung \\
\hline 4 & 52 & $\mathbf{M}$ & Recurrent pneumonia & 600 & Left lower lobe \\
\hline 5 & 46 & $\mathbf{M}$ & Tuberculosis & 600 & Left upper lobe \\
\hline 6 & 28 & $\mathbf{M}$ & Bronchiectasis & 1000 & Right upper lobe \\
\hline 7 & 58 & $\mathbf{M}$ & Tuberculosis & 600 & Left upper lobe \\
\hline 8 & 39 & $\mathbf{M}$ & Tuberculosis & 600 & Left lung \\
\hline 9 & 44 & $\mathbf{M}$ & Tuberculosis & 1000 & Left lung \\
\hline 10 & 36 & $\mathbf{M}$ & Lung abscess & 1000 & Left lung \\
\hline 11 & 45 & $\mathbf{M}$ & Giant pulmonary hamartoma & 900 & Right lower lobe \\
\hline 12 & 29 & $\mathbf{M}$ & Bronchiectasis & 1000 & Right upper lobe \\
\hline
\end{tabular}

were obtained in the x-ray department as an emergency. All blood coughed up was collected and its volume estimated. Antibiotics were given if the sputum was frankly purulent. If the volume of haemoptysis exceeded $600 \mathrm{ml}$ within 24 hours or less, emergency rigid bronchoscopy and cold saline pulmonary lavage was carried out and suitable preparations for an immediate thoracotomy were made. The diagnosis, the volume of haemoptysis and the localisation of bleeding at endoscopy for each patient are summarised in table 1.

The technique of rigid bronchoscopy in thesc actively bleeding patients differs in several aspects from the routine. An electrocardiograph was connected to the patient. General anaesthesia was induced, often with the patient propped up on the transport trolley after some preoxygenation. An adult-sized rigid bronchoscope was introduced through the vocal cords into the trachea. A wide bore oesophagoscopy sucker was used for speedy evacuation of blood and clot from the major airways. The bronchoscope was then advanced to intubate the main bronchus on the non-bleeding side. Oxygenation was maintained using the Sanders injector device or by inserting an endotracheal tube into the proximal end of the bronchoscope and intermittently insufflating with oxygen. A period of gas exchange then permitted stabilisation of the patient's condition. The 8 bronchoscope was next introduced into the $\vec{\circ}$ bronchus on the side of the bleeding and blood and clot were evacuated. Irrigation with normal $\vec{\nabla}$ saline at $4^{\circ} \mathrm{C}$ in $50 \mathrm{ml}$ aliquots was started. Each $50 \mathrm{ml}$ instillation was sucked out after $\stackrel{\mathbb{\Phi}}{\square}$ approximately 30-60 seconds, the normal side was 0 reintubated and gas exchange continued. By alternate intubation both gas exchange and $\overrightarrow{0}$ irrigation proceeded apace. As bleeding slowed ${ }^{\circ}$ in response to the cold irrigation, lobar localisation became possible, the appropriate lobar bronchus was then intubated and a local irrigation was carried out. There was a considerable reduction of bleeding after several cold saline instilla- $\frac{\text { Dे }}{8}$ tions. The bronchoscope was then withdrawn into the trachea between irrigation periods, permitting the use of both lungs for gas exchange. The average volume of irrigation fluid was $500 \mathrm{~m}$ per patient (range $300-750 \mathrm{ml}$ ), when all apparent bleeding had ceased and all blood and clot had ${ }_{\hat{O}}^{\vec{*}}$ been removed from both lungs a routine examination of the tracheobronchial tree was performed. $\stackrel{x}{-}$ Washings were collected for bacteriological and 3 cytological examination. General anaesthesia was reversed at this point, the patient was posturedB thereafter with the pathological lung dependento and our conservative regime was restarted. Table 2 contains a summary of the endoscopic ando

Table 2 Management and results

\begin{tabular}{|c|c|c|}
\hline Case & Management & Result \\
\hline $\begin{array}{l}1 \\
2\end{array}$ & $\begin{array}{l}\text { Bronchoscopy and cold lavage } \times 2 \\
\text { Bronchoscopy and cold lavage } \times 2 \\
\text { Extrapleural pneumonectomy }\end{array}$ & $\begin{array}{l}\text { Free of haemoptysis at one year } \\
\text { Well one year after operation }\end{array}$ \\
\hline 3 & $\begin{array}{l}\text { Bronchoscopy and cold lavage } \\
\text { Extrapleural pneumonectomy }\end{array}$ & Well one year after operation \\
\hline 4 & & Discharged free of haemoptysis at three weeks. Refused operation \\
\hline $\begin{array}{l}5 \\
6\end{array}$ & Bronchoscopy and cold lavage & $\begin{array}{l}\text { Discharged free of haemoptysis on TB chemotherapy } \\
\text { Discharged free of haemoptysis. Refused operation }\end{array}$ \\
\hline 7 & $\begin{array}{l}\text { Bronchoscopy and cold lavage } \\
\text { Bronchoscopy and cold lavage }\end{array}$ & Discharged free of haemoptysis on TB chemotherapy \\
\hline 8 & Bronchoscopy and cold lavage & Discharged free of haemoptysis on TB chemotherapy \\
\hline 9 & Bronchoscopy and cold lavage & Discharged free of haemoptysis on TB chemotherapy \\
\hline 10 & Bronchoscopy and cold lavage & Discharged free of haemoptysis. Refused operation \\
\hline 11 & Bronchoscopy and cold lavage & Discharged free of haemoptysis. Died three months later in respiratory failure \\
\hline 12 & $\begin{array}{l}\text { Bronchoscopy and cold lavage } \\
\text { Anterior segmentectomy of right upper lobe }\end{array}$ & Asymptomatic six months after operation \\
\hline
\end{tabular}


operative procedures performed, treatment given, and available follow-up.

\section{Results}

All patients stopped bleeding during the endoscopy and lavage, and no patient required emergency thoracotomy. The haemorrhage was shown to be localised to a lobe, segment group or segment in seven patients and lateralisation was possible in the other five patients. A transient sinus bradycardia was observed in one patient during the cold irrigation. Two patients suffered further episodes of massive haemoptysis during the same hospital admission, three days and 10 days after the initial procedure. One of these patients had refused operation, while the second patient had poor respiratory function and was in severe heart failure making any operation extremely hazardous. Both these patients were controlled by a second bronchoscopy and cold saline lavage. Four patients had active tuberculosis. Five patients had bronchiectasis with superimposed fungal or bacterial infections. One patient had a lung abscess and one had a postaspiration chronic destructive pneumonia. The remaining patient had a giant pulmonary hamartoma. Of the five patients with bronchiectasis, three subsequently had elective pulmonary resections and two refused operation. The remaining patients were treated medically. All patients were discharged from hospital free from haemoptysis.

\section{Discussion}

The massive spillage of blood into the tracheobronchial tree necessitates urgent bronchoscopic localisation of the bleeding site and expeditous treatment either an interim endoscopic control measure or immediate resection of the diseased pulmonary parenchyma. ${ }^{2-4}$ The decision to undertake an emergency operation is easily made when bleeding has been localised and controlled and the pulmonary reserve of the patient is known to be adequate for the proposed resection. The medical management of massive, life-threatening haemoptysis may incur a mortality of between $50 \%$ and $80 \% .{ }^{15}$ o Substantial reduction in mortality with surgical management has been reported by Crocco et al, ${ }^{\prime}$ McCallum et $a l^{3}$ and Mattox and Guinn. ${ }^{7}$ Howmanagement has been reported by Crocco et al, ${ }^{1}$ remains between $22 \%$ and $37 \% .{ }^{3} 5$ The surgical mortality occurs in those patients actively bleeding at the time of operation as defined by
Crocco et al. ${ }^{1}$ Often excluded from surgical series, but included in medical series and making a large contribution to the high mortality, are those patients suffering from disseminated pulmonary carcinoma, coagulopathies, serious cardiac disease, or severely compromised lung function. Mortality is also high in those patients in whom the localisation of bleeding has not been achieved, and in those refusing operation. Saw et $a l^{1}$ introduced endobronchial balloon tamponade using the flexible bronchoscope and controlled life-threatening haemcptysis in 10 successive patients. Remy et al ${ }^{8}$ reported on 104 patients with life-threatening haemoptysis managed by bronchial artery embolisation. Forty-seven of their patients were actively bleeding at the time of intervention and control of haemorrhage was achieved in all. Wholey et $a l^{6}$ reported control of massive haemorrhage in all five patients managed by bronchial arterial embolisation. Endoscopic control may also be achieved by endobronchial tamponade with a pack or swab, topical application of adrenaline solutions or the separation of bleeding and non-bleeding lungs with a double lumen endotracheal tube.

Although the flexible fibreoptic bronchoscope is the instrument of choice for most cases of haemoptysis, massive life-threatening haemoptysis is best managed with the rigid bronchoscope. The narrow suction channel of the flexible instrument is incapable of evacuating large volumes of blood rapidly and the optical system becomes obscured in the presence of large amounts of endobronchial blood. The rigid instrument excels both as an assured airway and as a conduit for the passage of large suction cannulae. The widespread adoption by many disciplines of flexible bronchoscopy has resulted in fewer applications of the rigid bronchoscope, but training in its use should remain an essential part of thoracic surgery programmes.

Massive haemoptysis was caused by inflammatory disease of the pulmonary parenchyma in 11 of our 12 patients. The pulmonary reserve of the majority of our cases was assessed clinically as marginal or was unknown. All patients were actively bleeding and their lives were in danger. Emergency operation would have carried a considerable mortality. The endoscopic cold saline irrigation technique proved effective and safe. The respite from haemoptysis allowed more accurate clinical and respiratory assessment of the patients and for a definitive diagnosis to be made in all. The patients suitable for pulmonary resections were defined and after bronchography were subjected to elective and where 
applicable, lung-sparing pulmonary resection.

Massive bleeding into the tracheobronchial tree is usually from the bronchial arterial system. The injection studies of the bronchial vasculature in inflammatory disease of the pulmonary parenchyma carried out by Cudkowicz ${ }^{9}$ in 1952 and Marchand et $a l^{10}$ in 1950, confirm this observation. Pulmonary arterial branches to inflamed areas of lung are thrombosed and obliterated early on in the inflammatory process. Bronchial arterial vessels enlarge as do "connecting vessels" between the bronchial and pulmonary arterial systems. These thin-walled, enlarging vessels carrying blood at systemic pressure traverse inflamed and necrotic areas of lung, and once breached flood the tracheobronchial tree. Marchand et $a l^{10}$ demonstrated not only increased bronchial arterial blood flow to areas of parenchymal inflammation in the lung, but also increased vascularity of that particular lobe and lung. The success of bronchial artery embolisation techniques in controlling massive haemoptysis corroborates the role of these vessels in life-threatening bleeding. The bronchial arteries contain the vasoresponsive mural musculature, typical of systemic arterial vessels. We believe that vasoconstriction occurs in response to the cold irrigation solution resulting in considerable reduction of blood flow and favouring thrombotic occlusion of the distal breached vessels. Saline irrigation of the lung has been used successfully in various pulmonary disorders, such as fibrocystic disease and alveolar proteinosis. Our technique uses modest volumes of cold irrigation fluid and is clearly a temporary control measure. Blood and clot are evacuated from the lungs, restoring lost function, and a respite from further bleeding is gained in the short term.

The availability of non-surgical methods for the early control of life-threatening haemoptysis should obviate the need for emergency surgical operation under hazardous circumstances. Lifethreatening haemorrhage can be temporarily controlled, restoring clinical stability, and allowing time for the underlying pathology to be defined and the patients' respiratory status to be determined. Resection if indicated can be carried out as a precise and elective procedure and the needless removal of healthy pulmonary tissue can be avoided.

\section{References}

1 Crocco JA, Rooney JJ, Fankushen DS. Dibenedetto RJ, Lyons HA. Massive haemoptysis. Arch Intern Med 1968; 121:495-8.

2 Selecky PA. Evaluation of hemoptysis through the bronchoscope. Chest 1978; 73:741-5.

3 McCollum WB, Mattox KL, Guinn GA, Beall AC. Immediate operative treatment for massivc hemoptysis. Chest 1975; 67:152-5.

4 Saw EC, Gottlieb LS, Yokoyama T, Lee BC. Flexible fiberoptic bronchoscopy and endobronchial tamponade in the management of massive hemoptysis. Chest 1976; 70:589-91.

5 Gourin A, Garzon AA. Operative treatment of massive hemoptysis. Ann Thorac Surg 1974; 18: 52-60.

6 Wholey MH, Chamorro HA, Gopal R, Ford WB, Miller WH. Bronchial artery embolization for massive hemoptysis. JAMA 1976; 236:2501-4.

7 Mattox KL, Guinn GA. Emergency resection for massive hemoptysis. Ann Thorac Surg 1974; 17:377-83.

8 Remy J, Arnaud A, Fardou H, Giraud R, Volsin C. Treatment of hemoptysis by embolization of bronchial arteries. Diagnostic Radiology 1977; 33:33-6.

9 Cudkowicz L. The blood supply of the lung in pulmonary tuberculosis. Thorax 1952; 7:270-6.

10 Marchand P, Gilroy JC, Wilson VH. An anatomical study of the bronchial vascular system and its variations in disease. Thorax 1950; 5:207-21.

11 Gottlieb LS, Hillberg R. Endobronchial tamponade. Therapy for intractible hemoptysis. 옹 Chest 1975; 67:482-3.

12 Harley JD, Killien FC, Peck AG. Massive hemoptysis controlled by transcatheter embolization of the bronchial arteries. Am J Roentgenol $\sigma$ 1977; 128:302-4. 